\title{
A DIMENSÃO CULTURAL DA IMIGRAÇÃO
}

\section{Giralda Seyferth}

Os conceitos de assimilação e aculturação marcaram alguns dos principais estudos sobre a imigração no Brasil realizados no âmbito das ciências sociais até o início da década de 1970. Os pesquisadores estavam interessados nas mudanças socioculturais e comportamentais envolvidas na inserção dos imigrantes na sociedade brasileira. No entanto, as análises realizadas apresentaram evidências da pluralidade cultural e da formação de novas identidades fundadas na diferença cultural, assuntos de pouco interesse quando o foco é o processo de absorção ou integração dos imigrantes na sociedade nacional. Por outro lado, as teorias mais recentes sobre processos migratórios deram maior atenção às questões econômicas e políticas envolvendo a migração em larga escala, em consonância com a globalização. ${ }^{1}$
O fenômeno migratório também produz etnicidade, palavra-chave nas análises de sistemas interétnicos amplamente usada nas últimas décadas com implicaçôes nas políticas de reconhecimento (inclusive aquelas associadas ao multiculturalismo e aos direitos de minorias). A delimitação teórica agrega a identidade (e seus aspectos subjetivos) e a noção de fronteira (social) que delimita o pertencimento a um grupo ou comunidade. Na prática, são enfatizados discernimentos sobre a simbólica da diferença cultural e os valores que orientam comportamentos. Contudo, alguns autores observaram que etnicidade, identidade e cultura são coisas distintas, não havendo necessariamente uma relação de causa-efeito entre elas. Mas, paradoxalmente, são fenômenos entrelaçados, observáveis também nos contextos migratórios. ${ }^{2}$

As teorias da migração nem sempre contemplam a cultura, assunto tão relevante quanto as representações da identidade construídas por indiví- 
duos e grupos a partir dela, formando enunciados simbólicos que apontam a ideologia como sistema cultural, uma proposição teórica de Geertz (1964) apropriada por Aronson (1976) para refletir sobre a etnicidade como um tipo particular de ideologia. Aliás, a noção de diferença cultural, no caso da imigração, remete às ideologias de pertencimento e seus usos, inclusive políticos, diante das situações de desigualdade no âmbito do Estado-nação. Cultura e etnicidade, portanto, estão relacionadas e sua propriedade pode ser observada na proposição conceitual de Abner Cohen que considerou etnicidade "uma forma de interação entre grupos culturais operando em contextos sociais comuns" (1974, p. XI).

Este trabalho tem por objetivo analisar a dimensão cultural da imigração, em consonância com etnicidade, a partir de um "estudo de caso" relativo à colonização estrangeira no contexto dos deslocamentos mais significativos de europeus para o Brasil. Trata-se de analisar um segmento abonado de "colonos alemães" estabelecidos no Vale do Itajaí, em espaços urbanos que, sob a denominação de Stadtplatz, surgiram em lugares específicos para sediar a administração de cada núcleo colonial. Nesse caso, destaca-se, principalmente, a colônia Blumenau, por sua notoriedade como paradigma do "enquistamento étnico" produzido pela imigração, conforme o entendimento do nacionalismo brasileiro, sua importância na política estadual a partir da República, destacando-se lideranças assumidamente teuto-brasileiras em conformidade com Deutschtum (germanidade) em sua afirmação empírica e simbólica. Além disso, no Vale do Itajaí em geral, e na colônia fundada por Hermann Blumenau ${ }^{3} \mathrm{em}$ particular (em parte por causa dos laços com importantes figuras do meio acadêmico germânico), circularam viajantes, geógrafos e outros cientistas, migrantes de todos os matizes e, com eles, muitas ideias relacionadas com o nacionalismo alemão.

O período histórico, portanto, é o da "grande imigração” e da instauração da República de 1889, que põe em evidência a formação do Estado nacional permeada por um sistema mundial produzido, entre outras coisas, pela expansão do colonialismo e do capitalismo, e pela emigração em massa de europeus. Caracterizou-se por uma exacerbação nacionalista alimentada por um discurso assimilacionista radical em relação aos parâmetros luso-brasileiros de formação da nação, que exigia o "caldeamento" dos alienígenas (isto é, todos os imigrantes e descendentes não abrasileirados, estabelecidos no território nacional). Por meio deste estudo, que aborda a problemática da imigração alemã, é possível mostrar a circulação de ideias, saberes e valores e algumas das bases empíricas de um (sub)sistema cultural produzido pela colonização - considerado perigoso pelo nacionalismo - que permitiram o surgimento da etnicidade teuto-brasileira, destacando a perenidade desse fenômeno reportado ao transnacionalismo.

\section{Cultura e a simbologia da etnicidade}

Os primeiros estrangeiros que se fixaram no Vale do Itajaí, em 1836, eram alemães egressos da colônia de São Pedro de Alcântara (fundada em 1829 , pouco antes do corte de despesas que inviabilizou a colonização com imigrantes). Essa migração interna, porém, não produziu um núcleo colonial ali: eram poucas famílias e, de fato, os descontentes com a situação precária em São Pedro de Alcântara preferiram se estabelecer na capital da província, Desterro (Florianópolis), ou na vila portuária de Itajaí - duas localidades propícias às atividades comerciais. A colonização do vale só começou com a fundação de Blumenau, em 1850, já no contexto de abertura às iniciativas particulares. As empresas de colonização, formadas para essa finalidade, podiam receber por compra (ou concessão) áreas de terras devolutas de até seis léguas quadradas, para demarcá-las em lotes para venda a colonos-imigrantes (arcando também com as despesas de propaganda na Europa). Dessa forma, Hermann Blumenau, associado a um comerciante alemão estabelecido em Desterro, requereu terras devolutas e adquiriu pequenas áreas de particulares no médio vale do rio Itajaí-açu, para formar ali uma nova Heimat (pátria) com imigrantes de origem germânica. A colônia ficou conhecida dentro e fora do Brasil por causa do enunciado étnico do empreendimento, provavelmente inspirado no nacionalismo romântico anterior à unificação da Alemanha, e das publicaçōes que suscitou, especialmente os livros escritos pelo fundador com o intuito de atrair imigrantes 
e outras obras que destacaram suas características “alemãs", produzidas por visitantes ocasionais, pastores e outros migrantes temporários e viajantes ocasionais de grande notoriedade como J. J. von Tschudi; tema presente também na literatura ficcional de autores teuto-brasileiros que publicaram contos, romances e poesias em língua alemã antes da intervenção nacionalizadora do Estado Novo iniciada em 1937.

Hermann Blumenau não tinha motivações econômicas para emigrar e tampouco possuía recursos que permitissem a realização de um projeto de colonização em larga escala. Seu interesse pela colonização alemã no sul do Brasil surgiu a partir de um encontro com o cônsul do Brasil na Prússia, J. J. Sturz, em 1844, durante uma viagem à Inglaterra. O cônsul julgava possível realizar um grande projeto de colonização (no Brasil, ou no Uruguai), mas não chegou a fazer uma proposta formal ao governo brasileiro por considerar incompatível a coexistência da imigração com o regime escravista. ${ }^{4}$ Dois anos depois do encontro, Blumenau obteve o grau de doutor na Universidade de Erlangen, após concluir o curso de química, talvez pensando numa carreira acadêmica como naturalista, conforme observação de Fouquet (1999, p. 20). Por meio da inserção acadêmica e do próprio Sturz, conheceu pessoas notáveis como Humboldt e Martius, que deram apoio à sua proposta de colonização, recomendando-o às autoridades brasileiras. Antes de decidir realizá-la em Santa Catarina, percorreu o sul como representante da Sociedade de Proteção aos Imigrantes Alemães no sul do Brasil. Chegou à essa organização por intermédio de Alexandre von Humboldt, com a incumbência de avaliar as condiçôes para uma colonização em grande escala, mobilizando parte dos emigrantes que tinha como destino os Estados Unidos da América. Entre os imigrantistas brasileiros, tinha apoio do marquês de Abrantes, que em 1846 era ministro plenipotenciário em Berlim, incumbido, entre outras coisas, de obter consentimento do governo prussiano para a atuação dos agenciadores de emigrantes para o Brasil.

A missão diplomática de Abrantes não foi bem-sucedida pois, em 1859, a Prússia promulgou decreto que dificultava a emigração para o Brasil. Isso foi motivado pelas denúncias acerca das condições precárias das colônias no sul, da servidão associada aos contratos de parceria nas fazendas paulistas e do discurso das autoridades brasileiras sobre a substituição do escravo pelo trabalhador livre imigrante, objeto da crítica de Sturz.

Os planos de colonização dessa sociedade não se concretizaram. Era necessário grande aporte financeiro (que precisava ser captado na Europa) e uma propaganda eficiente que pudesse "desviar" a corrente emigratória que tinha como destino a América do Norte, particularmente os Estados Unidos, ${ }^{5}$ num período em que os próprios governos alemães, sobretudo o da Prússia, colocavam entraves ao agenciamento de emigrantes para o Brasil. Além disso, o custo da viagem para a América do Sul era muito maior, e os riscos da longa travessia marítima na primeira metade do século XIX eram grandes, registrando-se altos índices de mortalidade, principalmente entre aqueles que viajavam de forma mais precária. ${ }^{6}$ Mesmo assim, Blumenau propôs ao governo brasileiro um projeto menos ambicioso, inclusive porque a "grande escala” pretendida não estava de acordo com o modelo sancionado para a iniciativa particular. Apesar do interesse no povoamento/colonização vinculados à imigração europeia, que aponta à questão da formação do Estado e da consolidação do território nacional, havia certo cuidado, inclusive no Ministério do Império, em relação a projetos de grande monta, sendo autorizadas, de acordo com a legislação, as propostas contidas no limite máximo de seis léguas em quadra. O Vale do Itajaí não foi a primeira opção, mas aquela que, de fato, deu certo, após um período de quatro anos percorrendo gabinetes, conversando com ministros e parlamentares na Corte e na Assembleia Provincial de Santa Catarina.

A pertinácia de Hermann Blumenau é notável, em parte explicada pelo sentido de missão, defendendo uma "causa" (a formação de "colônias alemãs" cultural e nacionalmente configuradas), de certo modo inculcada por Sturz, mas também por Martius, Wappäus e outros que escreveram sobre o Brasil, assim como Humboldt - todos indivíduos com grande prestígio acadêmico também preocupados com a emigração dos seus compatriotas e os movimentos sociais que culminaram com a revolução de 1848. Tratava-se de dar oportunidade aos 
emigrantes (motivados por razões econômicas e/ou políticas) de formar uma nova pátria (obviamente germânica) num outro país - um tipo de territorialização considerado viável no formato da colonização tendo em vista a sinonímia com povoamento (o que foi o caso da colônia fundada no Itajaí-açu).

Não pretendo analisar essa colonização, que seguiu as normas da legislação brasileira; ${ }^{7}$ deve-se destacar, porém, que Blumenau e seus auxiliares mais próximos viajaram muitas vezes para a Alemanha para recrutar emigrantes que pudessem viajar sem subsídios e, em alguns casos, para casar, mantendo contatos com pessoas notáveis. Por outro lado, o empreendimento foi visitado por um grande número de compatriotas, muitos dos quais ali permaneceram por vários anos. O casal Gustav (um pastor protestante) e Therese Stutzer é um bom exemplo: eles viveram em Blumenau durante quase uma década e, voltando para a Alemanha, publicaram vários livros sobre a região e também obras de ficção, acentuando o "caráter" germânico da colônia, que consideravam uma pequena Alemanha no Brasil. ${ }^{8}$ Os Stutzer, porém, são apenas um exemplo da vasta produção em língua alemã sobre o Vale do Itajaí (tão importante quanto os trabalhos publicados em língua portuguesa) como pode ser observado nas resenhas realizadas por Fouquet (1950) e Seyferth (1988).

Assim, a circulação de pessoas entre Blumenau e a Alemanha foi bastante significativa, mostrando fortes laços com a Urheimat (velha pátria) mesmo na situação de isolamento enfrentada na primeira década da colonização. Apesar disso, o empreendimento enfrentou dificuldades, pois, sendo particular, dependia de um fluxo relativamente intenso de imigrantes para cobrir os gastos da demarcação, abertura de caminhos, construção de prédios públicos (inclusive escolas) e outros encargos assumidos pela empresa, através da venda dos lotes aos colonos. Blumenau não conseguiu atrair um número necessário de compatriotas, apesar do grande movimento emigratório alemão. $\mathrm{A}$ iniciativa não fracassou porque o governo imperial assumiu a colonização em 1860, ano em que foi fundada outra "colônia alemã", oficial, no Itajaímirim - Brusque. Não existia mais o empresário colonizador, mas Blumenau foi mantido na direção da colônia até sua emancipação política, como município, no início da década de 1880 , ocasião em que retornou definitivamente para a Alemanha.

Transformado em região de colonização oficial, o médio Vale do Itajaí passou a ser o destino de imigrantes alemães atraídos pelos subsídios, via agenciadores a serviço do governo imperial. Isso mudou o perfil do colono, pois, a partir de 1875 , começaram a chegar imigrantes de outras origens nacionais, notadamente italianos e poloneses. $\mathrm{O}$ que antes era um projeto de nova Heimat para alemães protestantes, criticado com veemência pela igreja católica, agora recebia não só alemães católicos, mas também gente de outras nacionalidades. Manteve-se, porém, o epíteto de "colônias alemãs" para os principais núcleos coloniais, até porque a maioria da população, na virada do século XX, era de origem germânica e o subsistema cultural ali formado deu respaldo ideológico a essa qualificação. A notoriedade do Vale do Itajaí como lugar de "colonização alemâ" deve-se, em grande parte, à atuação de Hermann Blumenau e aos viajantes e outros personagens - aí incluídos os imigrantes "temporários" que retornaram, caso dos Stutzer que ajudaram a criar a imagem de um lugar balizado pelos valores da germanidade (Deutschtum).

Ao tratar do status ontológico do termo etnicidade, Fenton observou que ele diz respeito à descendência e à cultura. Considera isso um ponto de partida e não simplesmente uma definição, e o ponto seguinte é pensar que etnicidade "se refere à construção social da descendência e da cultura, à mobilização social da descendência e da cultura, e ao significado e implicaçôes dos sistemas classificatórios construídos em torno dela" (2008, p. 3). Povos não possuem apenas culturas ou ancestralidade compartilhada, eles elaboram as duas coisas para compor uma ideia de ancestralidade que cerca as definições de grupos ou comunidades, procura mostrar que os rótulos étnicos (ou outras categorias) não estão no vazio, tem uma base real a sustentá-los. De outro modo, Max Weber (1991, p. 270) também apela a princípios semelhantes ao tratar das coletividades (ou comunidades) étnicas e de nação, destacando a crença na afinidade de origem (objetivamente fundada ou não) e os habitus, costumes etc., fazendo referências, inclusive, à imigração. 
Cultura e etnicidade estão entrelaçados, o que põe em evidência a diferença (em relação aos "outros") e o embasamento da identidade. Então, no que consiste, empiricamente, a cultura teuto-brasileira na virada para o século XX, marcada pela configuração da colônia Blumenau nos seus primórdios (com extensão para outras "colônias alemãs" da região)? Cabe, fazer referência à política de colonização voltada para a localização de imigrantes em terras devolutas, um procedimento que não ameaçava os interesses da grande propriedade monocultora. Esse regime de povoamento de áreas de florestas e sem vias de comunicação terrestre caso das colônias de Blumenau e Brusque - foi idealizado no âmbito do aparelho de Estado sem incluir potenciais colonos brasileiros. Nas primeiras décadas, a maior parte dos imigrantes, e mesmo a segunda geração, teve pouco ou nenhum convívio com a sociedade nacional, e isso teve reflexos na formação comunitária étnica, tanto quanto a ideia mais geral de, naquele lugar, territorializar a nova Heimat (na sua associação com o lar). É claro que o próprio regime de colonização, baseado na pequena propriedade familiar, era bem diverso do meio rural brasileiro, ajudando a compor a diferença sociocultural, assim como a "aculturação ergológica" assinalada por Willems (1946) para referir-se aos novos padrōes de alimentação, moradia, vestuário, tecnologia etc. - mudanças relacionadas com a cultura material e a adaptação ao novo meio ambiente.

Essa especificidade não tem grande importância quando o assunto são os aspectos pragmáticos da etnicidade, relativos mais diretamente à dimensão cultural valorizada, e aí emerge, em primeiro lugar, o caráter distintivo da língua falada no cotidiano das colônias. $\mathrm{Na}$ prática, a ideia de Heimat, e seu qualificador, a germanidade, supóe o uso comum da língua alemã, uma característica enfatizada em vários textos e depoimentos, seja de viajantes ocasionais, seja de colonos comuns. Veja-se, por exemplo, as impressões de viagem de Wilhelm Lacmann, que esteve no Vale do Itajaí (e em outras áreas de colonização de Santa Catarina e do Rio Grande do Sul) em 1903. No livro publicado em 1906, compara Blumenau a uma "pequena cidade alemã das montanhas", um lugar onde a língua alemã se preservou, apesar da incorporação de expressões idiomáticas relativas ao meio ambiente; e acrescenta (numa observação mais geral): "As colônias, sob o meu ponto de vista, podem ser consideradas deutsches Gebiet", uma região de caráter alemão. Nestas colônias foram conservadas a língua, os hábitos e os costumes germânicos. Também não desapareceu o sentimento de afinidade com o povo alemão"?

De modo mais enfático, Gustav Stutzer também faz questão de destacar o uso cotidiano da língua alemã em Blumenau, enquanto seus compatriotas que emigraram para a América do Norte trocaram sua bela língua materna "pelo horrível som da língua yankee". ${ }^{10}$

Tais publicações podiam ter eficácia limitada como propaganda, mas muitas vezes influenciaram a decisão de emigrar. Por outro lado, entre os "documentos originais" publicados pela revista Blumenau em Cadernos nos contextos comemorativos do sesquicentenário de Blumenau e do centenário da morte de Hermann Blumenau, encontram-se memórias, vivências e escritos variados de imigrantes, em que são delineados, além da questão da língua, outros aspectos da especificidade cultural. Um bom exemplo é o texto intitulado "Erlebnis von Klara Hermann" "Experiência de Klara Hermann) - um relato sobre a vida na colônia no início do século XX, precedido pela motivação para emigrar. A percepção da germanidade local aparece no texto quando descreve sua passagem por Joinville (uma "colônia alemā") a caminho do Vale do Itajaí:

Em São Francisco me senti como se estivesse em um país estrangeiro, mas Joinville tirou essa impressão, aqui só se ouvia falar alemão e a cidade tinha o aspecto de uma cidadezinha alemã. $\mathrm{O}$ que nos transmitiu esta impressão certamente eram os jardins ao redor das casas com suas flores exuberantes. Também havia belas rosas. Cada qual procurava reproduzir um pouco a pátria mãe. Apenas a bela Alameda das Palmeiras lembrava o Brasil.

Aí está a impressão inicial de uma imigrante recém-chegada, que desembarcou em São Francisco (do Sul), localidade portuária surgida no Brasil-Colônia, e logo em seguida adentra a região 
colonizada pela Sociedade Colonizadora de 1849 em Hamburgo, e cujo polo urbano era a cidade de Joinville. Além da alusão linguística, é interessante observar que o outro aspecto distintivo destacado no texto diz respeito à Wohnkultur ou, de modo mais objetivo, ao lar, à casa e seu entorno (o jardim) - referência básica da ideia de Heimat, termo derivado de Heim (lar), o que explica a ênfase geral da construção de uma nova pátria no Brasil. A imagem (elaborada) da chegada ao destino (o lote colonial recebido pelo marido na colônia Hansa-Humboldt, situado além de Blumenau) também é significativa:

Chegamos a um vale verde cortado por inúmeros rios, rodeado de morros, o qual nos trazia à memória a paisagem da floresta da Turíngia, havendo alemães tanto aqui como lá. No Stadtplatz (centro da colônia) já havia algumas casas de aparência simpática, três vendas e um hotel, mas nós continuamos nosso caminho através da mata virgem e, finalmente, chegamos ao nosso destino. As crianças vizinhas me aguardavam à beira da estrada com flores. Crianças louras de olhos azuis, nascidas aqui, vieram dar-me as boas vindas. Nossa casa ficava em meio a um pasto rodeado de um pequeno jardim.

As duas transcrições falam por si mesmas. $\mathrm{O}$ estranhamento em relação à cidade brasileira desaparece diante da familiaridade da nova Heimat e sua paisagem (cultural), do encontro com compatriotas, pois havia alemães naquele lugar do Brasil que mantinham a língua e as tradições. A imigração, afinal, podia se concretizar sem um rompimento radical com as origens.

A menção à casa já existente nas terras compradas pelo marido-colono pode parecer estranha, numa situação de colônia nova, ainda cercada pela floresta. A explicação está no motivo da emigração: o casamento. O marido de Klara Hermann estava estabelecido ali há 4 anos, a propriedade já estava "desbravada", tinha casa e jardim. Ele viajou para a Alemanha com o intuito de visitar a irmã e encontrar uma esposa. Lá (na Alemanha) era identificado como "brasileiro" - um imigrante. Buscar esposa na Alemanha certamente não era coisa corriqueira, mas ocorria nos segmentos mais abonados, inclusive entre os colonos. Num período marcado pelo crescimento econômico da região como um todo, as viagens para a Alemanha tornaram-se comuns. Além disso, o fluxo imigratório, embora pequeno, persistiu por causa da continuidade da colonização e do início da industrialização em Blumenau e Brusque, demandando mão de obra qualificada recrutada na Alemanha pelos empresários locais. O trânsito de pessoas na dupla rota da imigração contribuiu para reforçar o ideal de Deutschtum, presente no texto de Klara Hermann de forma aparentemente prosaica através do Heim (lar). No entanto, casas e jardins também aparecem como algo diferente, peculiar e valorizado, em alguns escritos sobre o Vale do Itajaí produzidos por brasileiros, viajantes ou lá radicados, em tempos mais recentes. A representação de Klara Hermann sobre a casa está presente num texto historiográfico de Max Tavares d'Amaral, publicado no ano de comemoração do centenário da fundação de Blumenau. Segundo o autor:

O alemão, a primeira cousa que faz quando se estabiliza economicamente, quando começa a produzir, é substituir sua casinha tosca, primitiva, por outra melhor, até chegar a residência confortável de tijolos com suas cortinas na janela, seu jardim e seu pomar que são o seu orgulho e constituem o ornamento por excelência da paisagem colonial. Parece poder dizer-se que a casa é o traço característico do colono alemão, o traço que o distingue dos demais. Ele pode perder todas as características da raça - a língua, as tradiçôes, mas não perde nunca o hábito de morar em boa casa, quando suas condiçōes econômicas o permitam (D'Amaral, 1950, p. 63).

Atribui às condições de habitação um valor histórico social, afirmando que a ideia do Heim como "o mundo do colono", trazida do país de origem, relaciona-se com a "Wohnkultur, isto é, o hábito de morar bem", diferenciando-se do homem rural brasileiro e até mesmo de outros colonos europeus. A discussão sobre a moradia indica sua apropriação como elemento distintivo da "cultura teuto-brasileira" por causa da sua visibilidade. Willems procurou mostrar que as casas não têm as mesmas 
características na Alemanha, sobretudo as construções de madeira, comuns em todo o sul do Brasil. No entanto, afirma que as diferenças (em relação aos brasileiros) surgem num dado momento, quando colonos prósperos utilizam nas construções "as experiências de sua cultura anterior". O referencial é principalmente a casa no "estilo enxaimel", construída de tijolos com madeira à mostra. Aparentemente irritado com o discurso generalizado em torno da moradia, diz:

Quando todos os observadores que mui superficialmente descreveram a casa dos teuto-brasileiros, como se houvesse sido importada já feita da Alemanha, em geral ignoram o fato de que não existe uma "casa alemâ" como não existe uma "cozinha alemâ" (Willems, 1946, p. 231).

$\mathrm{Na}$ lógica da teoria da aculturação, que embasa a análise de Willems, essa observação faz sentido porque remete à mudança cultural, porém encobre o fato da apropriação (simbólica, inclusive) de um traço cultural relevante na construção da diferença étnica com repercussão na identidade teuto-brasileira. O caráter distintivo da moradia, ou do lar, está presente na literatura sobre o Vale do Itajaí, sobretudo nos trabalhos orientados pela noção de Deustchtum, mas também nos discursos de senso comum. A distinção fica ainda mais marcante na sobreposição entre a casa e a língua alemã. Em suma, além da Wohnkultur, num Heim alemão deve predominar o uso do idioma alemão. A simbiose lar(casa)-língua chamou a atenção dos observadores, inclusive os brasileiros, ao longo de boa parte do século XX. E a casa do discurso folclorista atual é aquela que a maioria dos observadores chamam de "típica" -construída no modelo enxaimel. ${ }^{12}$

Num caso extremo de xenofobia em relação ao perfil "germânico" de Blumenau, a diferença incômoda estava na língua, nas casas, nos cemitérios, nas ruas batizadas com nomes estranhos, na circulação de um número excessivo de bicicletas, nas igrejas, no comportamento público das mulheres casadas, em toda parte. Para Rui Alencar Nogueira, um militar participante da nacionalização imposta pelo Estado Novo, o Vale do Itajaí era um território dominado por estrangeiros, onde se justificava o "abra- sileiramento" forçado. Daí expressar seu sentimento de aversão, pois naquele lugar não existia o Brasil (cf. Nogueira, 1947). A exigência de abrasileiramento, ou assimilação completa nos cânones da formação luso-brasileira, vinha do final do século XIX, na voz de Silvio Romero e outros críticos da diversidade étnica produzida pela imigração. A preocupação com a integridade territorial e cultural do Estado-nação ficou mais evidente a partir da República de 1889, momento histórico em que Blumenau (e a colonização alemã em geral) se tornou exemplo de "enquistamento étnico". A comparação dos textos de Nogueira e Klara Hermann, porém, mostra o mesmo princípio de estranhamento (e inconformismo) diante do desconhecido e ao mesmo tempo novo: no primeiro caso, manifesta-se no relato da chegada do batalhão do exército a Blumenau, que deixou todos "contrafeitos" de estar numa cidade que não era brasileira; no segundo caso, entra em cena o desembarque em São Francisco do Sul, uma cidade brasileira, estrangeira, que traz à memória o rompimento da imigrante com a pátria, mas logo depois reencontrada na região de colonização alemã.

O lar e a língua são associados de modo direto a uma concepção cultural de nação, no sentido particularista do nacionalismo romântico postulado por Herder, autor eventualmente citado na imprensa em língua alemã que se consolidou no Vale do Itajaí antes da Primeira Guerra Mundial. Isto não diminuiu a importância da pertença étnica de conteúdo primordial, confundida com ascendência e subsumida pelo termo "origem", às vezes referido à raça. No outro extremo da lógica particularista, o modo de vida, os hábitos alimentares, as atividades econômicas e outros aspectos do complexo colonial compartilhados com colonos de outras procedências nacionais também são apropriados como marcadores étnicos no confronto com o "outro" mais distanciado - o brasileiro.

No campo subjetivo, a roça do colono alemão tem sua especificidade associada a um ethos do trabalho próprio da etnia e não à forma de cultivo; e a individualidade dos hábitos alimentares permite vincular o consumo da polenta aos italianos, e o pão, aos alemães, mas na colônia ambos são feitos de milho e estão na cozinha dos dois grupos. Por outro lado, no cotidiano não havia muita es- 
colha, conforme mais um depoimento de Klara Hermann: em vez de batata come-se muito aipim, batata doce e feijão, e o Mus (doce de frutas) se faz de banana, laranja ou abóbora. No entanto, os costumes condicionam as formas de adaptação, pois todos têm bananas e laranjas, mas o Mus é alemão! As práticas cotidianas, habitus, modo de vida, organização social e outros aspectos da realidade cultural tem importância na contextualização da etnicidade. Nesse sentido, atribuem-se características étnicas ao modo de comemorar festas religiosas, como natal e páscoa, que são comum a todos os cristãos. Nos relatos de imigrantes sobre os tempos pioneiros na colônia Blumenau, a festa de natal, por causa do costume de armar a árvore e entoar canções apropriadas em língua alemã, evoca a pátria deixada para trás e ao mesmo tempo presente nesse outro lugar. ${ }^{13}$

As alusões à vida cotidiana, aos hábitos e costumes (na definição dos atores sociais) permitem vislumbrar algumas minúcias da cultura teuto-brasileira (para usar um conceito de Willems) passíveis de apropriação na contextualização da etnicidade, inclusive na atualidade. Mas devem ser destacadas também as instituições comunitárias formadas praticamente desde o início da colonização. Elas tiveram maior notoriedade como elementos de diferenciação cultural antes da campanha de nacionalização, iniciada em 1937; algumas conseguiram sobreviver - caso das sociedades de atiradores -, mantendo a adjetivação étnica. Atribuiu-se maior importância à "escola alemã”, considerada indispensável para perpetuar o ensino da língua materna, num contexto político (a Primeira República) onde eram discutidas a assimilação e o abrasileiramento. Na Deutsche Schule o ensino era dado em alemão e, na percepção dos atores sociais, a escola funcionava como uma extensão do lar na formação da teuto-brasilidade. Resumindo, o aprendizado da língua deve começar com a mãe, no lar, e tem prosseguimento na escola, e essa imagem foi bastante enfatizada na poesia e nos escritos produzidos por autores teuto-brasileiros sobre Deutschtum. A possibilidade da proibição do ensino em língua estrangeira, exigida pelo nacionalismo desde o início do regime republicano, provocou um contradiscurso baseado no direito à diferença, e esta dependia da existência de um lar e um sistema escolar empenhados na perpetuação do uso do idioma alemão. Esses elementos (lar, língua), junto com ascendência (origem), formam a base da própria definição da categoria étnica - Deutschbrasilianer - tal como aparece nas matérias de jornais e almanaques que circularam pelo Vale do Itajaí até 1939. A categoria supōe a manutenção da germanidade em solo brasileiro, daí tanta ênfase na ideia de Heimat. A versão mais poética presume um bom brasileiro com alma alemã.

As ideias sobre a germanidade circularam pela imprensa, anúncios e pela literatura ficcional voltada para temáticas relativas à colonização. Dois importantes jornais foram editados em Blumenau entre a década de 1880 e o Estado Novo - Blumenauer Zeitung e Der Urwaldsbote - controlados por facçōes políticas rivais, mas com uma coisa em comum - a germanidade. Ali também circularam publicações periódicas vindas de outras regiōes coloniais. ${ }^{14} \mathrm{Na}$ prática, essa circulação repercutiu nas representaçôes da etnicidade voltada para a dimensão cultural contida na ideia de Heimat, presente também na correspondência de Hermann Blumenau, onde o Vale do Itajaí é apresentado como "verdadeira pátria", conservando-se a nacionalidade alemã. ${ }^{15}$ A nação alemã, nesse caso, tem uma representação cultural, não política, permitindo equacionar a germanidade com a territorialização no Brasil.

Por fim, é preciso mencionar as associações recreativas e culturais destacadas pela maioria dos estudiosos da imigração alemã por causa da sua significância numérica e sua vinculação com o nacionalismo alemão. Espaços de convivência, lugares da sociabilidade, eram imaginados como expressão do "espírito (associativo) germânico". De fato, poucos anos depois da fundação, Blumenau e Brusque já possuíam sua Schutzenverein, uma associação historicamente vinculada ao nacionalismo alemão do início do século XIX. Depois das associações de atiradores vieram outras, igualmente situadas no contexto cultural teuto-brasileiro - , caso das sociedades de canto (Gesangvereine) e de ginástica (Turnvereine). Sua importância como expressão de etnicidade pode ser medida pela intervenção violenta do exército brasileiro nesses espaços durante a campanha de nacionalização: todas foram fechadas 
à força e algumas sedes sociais serviram para acantonar as tropas.

Havia associações em toda parte, nos centros urbanos e nas principais linhas coloniais (portanto, no meio rural). Não tinham apenas o perfil de agremiações esportivas ou recreativas, pois neles eram realizadas representações teatrais, sessões de música e outras atividades relacionadas com a noção de Kultur numa contextualização germânica que valorizava a "consciência" linguística e o Deutschtum. Várias sociedades de atiradores e de ginástica sobreviveram à nacionalização, mas as de canto, mais associadas à Kultur, desapareceram.

A imagem de uma comunidade étnica alicerçada nos valores da germanidade de certo modo foi reproduzida no volume comemorativo do centenário da imigração alemã em Santa Catarina (Entres, 1929), que condensa o período anterior à nacionalização. Ali aparece a poesia que honra a nova pátria, a pertença étnica; é destacada a vida do colono pioneiro, a escola alemã, as associaçôes, a paisagem cultural criada pelos imigrantes na Palmenland (a terra das palmeiras - o Brasil); por fim, faz apologia do desenvolvimento econômico em textos historiográficos, e numa visão progressista distingue os empreendedores que tiveram papel importante na economia, na política e na mediação étnica. A publicação teve apoio de uma editora alemã, significativamente denominada Ausland und Heimat Verlag - Haus des Deutschtums, coisa que evidencia o transnacionalismo.

\section{Os empreendedores e a "teuto-brasilidade"}

A ideia da formação de uma nova Heimat, ponto de partida do projeto colonizador de Hermann Blumenau, tem como principal fundamento a existência de uma cultura e um modo de vida diferenciados naquele contexto colonial. Mas a circulação da ideologia de pertencimento (a uma etnia alemã), articulada à reivindicação da legitimidade da diferença cultural diante das exigências assimilacionistas do nacionalismo brasileiro, põe em evidência os "mediadores" integrantes dos grupos urbanos em ascensão social, empreendedores distinguidos por uma identidade teuto-brasileira, e o uso instrumental da etnicidade.
Os aspectos econômicos e políticos das etnicidades têm sido destacados por vários pesquisadores, desde o surgimento desse neologismo na língua inglesa na década de 1950. Glazer e Moynihan (1963) discutiram o assunto num estudo clássico sobre alguns grupos etnicamente identificados da cidade de Nova York. Fizeram uma crítica à velha concepção de melting-pot, evitando as teorias de assimilação e aculturação ainda em evidência nos estudos da imigração e das relações interétnicas, procurando responder a uma pergunta básica: o que significa para Nova York o fato de a maior parte da sua população estar composta de pessoas que se pensam através de um pertencimento étnico, e mesmo assim se consideram norte-americanos? Concluem que existe uma tendência central no ethos nacional que estrutura as pessoas em grupos de diferentes status e características, um padrão étnico configurado por forte diferenciação (real ou imaginada) entre norte-americanos irlandeses, judeus, italianos e assim por diante, apontando a falência da noção de melting-pot. De fato, interessa reter da argumentação desses autores o destaque dado à vinculação entre etnicidades e interesses ou, dito de outra forma, olhar para os usos de identidades indicadoras de duplo pertencimento a partir da noção de "grupo de interesse", tendo em vista a dinâmica da recriação contínua do pertencimento grupal por intermédio de novas experiências, mesmo quando os descendentes de imigrantes, por exemplo, já perderam a maior parte dos vínculos culturais que os distinguiam dos outros norte-americanos. A identidade (étnica) permite associar o indivíduo, ou o grupo, a um passado, uma raça, uma cultura compartilhada, suscita sentimentos de pertença, mas o interesse comum também une, permitindo laços concretos de comunidade. Glazer e Moynihan analisaram o jogo político e, nele, o voto étnico. Outros autores, porém, apontaram para interesses políticos conformados por organizações corporativas de base econômica, como é o caso do estudo de Abner Cohen (1969) sobre as redes de comércio dominadas pelos Hausa, na África Ocidental, e que atravessam as fronteiras dos estados pós-coloniais. Ali, os Hausa usam e manipulam costumes, valores, mitos e símbolos da sua tradição cultural para articular uma organização informal, de natureza política e econômica - grupos 
definidos por uma etnicidade baseada na noção de cultura compartilhada e que agem como "grupos de interesse" numa circunstância de pluralismo étnico. O idioma do costume, nesse caso, é o marcador usado para delimitar grupos informais cujo poder deriva também (mas não exclusivamente) da hegemonia de uma atividade econômica.

A etnicidade é um fenômeno empiricamente muito variado, mas as abordagens mais instrumentais a apresentam como um recurso social, político e cultural para diferentes grupos étnicos e de status. Algumas versōes focalizam a competição por recursos (econômicos, políticos), outras examinam as estratégias para maximizar preferências em termos de escolhas racionais. A crítica sobre essa abordagem aponta para certos excessos que definem "interesses" em termos exclusivamente materiais e políticos. Mas poucos autores adotam apenas esse ponto de vista. Afinal, não existe etnicidade apenas por interesse, e nem é possível minimizar sua importância no mundo moderno.

A relação entre etnicidade, raça e nacionalismo, e sua natureza política e econômica envolvendo classe e status, já estava esboçada no texto de Weber (1991) sobre comunidades étnicas. Mas, descuidando da questão mais geral (ou cultural) da identidade, foi dada maior atenção aos processos políticos e/ou econômicos, nos quais a etnicidade é uma variável importante de organização coletiva - o pertencimento a uma etnia, nação etc. como estratégia para a ação corporativa, um instrumento de poder (cf. Cohen, 1969). Daí a ênfase de certos autores aos denominados ethnic entrepreneurs, categoria tomada na sua versão mais geral de "empreendedor" que, no sentido econômico, organiza, possui e administra um negócio assumindo seus riscos; muitas vezes possui o papel de mediador. Nos termos de Aronson (1976), a categoria empreendedor (ou empresário) étnico designa aqueles que formulam e administram ideologias e observam como as situações são definidas ou reforçadas para sua vantagem.

A colonização alemã no Vale do Itajaí é bastante significativa para tratar dessa categoria. O objetivo aqui certamente não é focalizar negócios étnicos (ethnic business) na sua dimensão econômica e individual. Pretende-se olhar para empreendedores com interesses econômicos e políticos conectados à etnicidade teuto-brasileira. Existem estudos sobre empresas étnicas, sobretudo nos Estados Unidos, onde são bastante comuns, que enfatizam a estrutura de oportunidades confrontando imigrantes nas sociedades capitalistas ocidentais, assim como a distribuição de recursos e as formas pelas quais são acessíveis às minorias (imigrantes ou não). Em geral, o enfoque recai no pequeno empresário que se volta para um mercado específico e onde os atores sociais são comerciantes, trabalhadores e consumidores étnicos e/ou imigrantes. Os estudiosos procuram olhar para o funcionamento desse mercado analisando os laços entre indivíduos e grupos com identidade comum, as redes sociais que mostram a mobilização dos empresários, as estratégias etc., dando especial atenção aos contextos imigratórios. ${ }^{16}$

Os primeiros empresários que se estabeleceram no Brasil após a abertura dos portos em 1808 eram comerciantes dedicados à exportação de café e à importação de artigos diversos da Europa. Formavam um grupo coeso no Rio de Janeiro, onde foi fundada a primeira associação étnica alemã do Brasil - Gesellschaft Germania - em 1821. Ao longo do século XIX, outros alemães se fixaram em cidades brasileiras na mesma atividade e também como empresários do transporte marítimo. Isso aconteceu na capital de Santa Catarina e no porto de Itajaí. Estes grupos ascenderam socialmente e também fundaram suas sociedades "Germania", talvez com um sentido mais elitista do que suas congêneres das áreas coloniais. $\mathrm{O}$ crescimento desse comércio pode ser vinculado ao interesse alemão no mercado sul-americano, expandido no período histórico aqui considerado. Isso produziu a circulação de bens e capitais, abrindo no país de acolhida espaço para mercadorias do país de origem. Esse tema teve amplo espaço na literatura sobre a colonização alemã, sendo defendida uma intensificação da imigração para tornar tais atividades de natureza econômica mais expressivas. Autores alemães e teuto-brasileiros que defenderam o aumento da imigração também falavam da germanidade. Na medida em que a Alemanha unificada entrou na disputa imperialista, em fins do século XIX, a sobreposição de interesses econômicos e etnicidade ajudou a dar respaldo ao discurso nacionalista antigermânico, alimentado também pela doutrina Monroe, em parte critica- 
da, mas igualmente aceita como defesa contra os interesses europeus na América do Sul. Falava-se em "perigo alemão" que alardeava o risco de perder o sul do país, cheio de colonos seduzidos pelo pangermanismo. $\mathrm{O}$ interesse econômico existia de ambos os lados; o mercado, porém, foi "etnizado" nas principais publicaçôes sobre as colônias que circularam naquele período.

Não foi diferente no Vale do Itajaí, onde as atividades comerciais eram dominadas por uma elite teuto-brasileira (imigrantes naturalizados). Os primeiros relatórios sobre a colônia Brusque, por exemplo, parecem indicar a tendência de predomínio de brasileiros nessa atividade, mas isso não se confirmou, predominando os empresários teuto-brasileiros. Os projetos coloniais não atraíram investimentos de brasileiros nessa área, talvez por causa da situação de frente pioneira, com vias de comunicação precárias. As primeiras casas comerciais surgiram em lugares destinados ao povoado sede de cada núcleo colonial. Funcionavam como ponto de abastecimento de alimentos para imigrantes que aguardavam a concessão de terra e lugar de trocas com os colonos já estabelecidos (compra dos excedentes da produção colonial e venda de equipamentos e outros bens). A relação comercial com os colonos estabeleceu uma polaridade rural-urbana característica de contextos camponeses. Aos poucos, apareceram pequenos comerciantes nos entroncamentos das linhas coloniais, que iniciaram suas atividades como proprietários de lote colonial (mantendo, em alguns casos, as duas atividades). Enfim, desenvolveu-se, com sucesso, uma exploração agrícola camponesa baseada na pequena propriedade familiar sem empregados (e também no artesanato), refletida nos relatórios das autoridades coloniais repletos de estatísticas da produtividade policultora. Nessa situação, fica evidente a sujeição dos colonos ao monopólio de preços e transporte imposto por seus compatriotas "vendeiros".

Quem eram esses comerciantes? A política de colonização privilegiou a vinda de agricultores e artesãos como imigrantes preferenciais. Na prática, entraram profissionais diversos e, na imigração espontânea, indivíduos que dispunham de pequenos recursos que permitiram iniciar um negócio. Nas linhas, alguns imigrantes amealharam dinheiro na atividade madeireira ou operando moinhos que atendiam a demanda de outros colonos. Por outro lado, a colônia de Blumenau (e, por extensão, o Vale do Itajaí), por seu perfil identificado com a germanidade, acentuado por publicações na Alemanha, atraiu imigrantes com perfil de empresários.

Juntamente com a expansão da área ocupada, e a criação de novas colônias que adentrou o século XX, formou-se uma rede de comerciantes de origem alemã que incluía os estabelecidos nas linhas, concentrando as firmas maiores em Blumenau e Brusque. Houve ampla diversificação com o surgimento de pequenas indústrias e oficinas de artesãos, mas prevaleceu o estabelecimento dos comerciantes mais abastados, nas cidades, que iniciaram a industrialização em fins do século XIX. A relação com os colonos baseou-se na confiança mútua, marcada pelo pertencimento étnico. A classe dos comerciantes foi a única que enriqueceu no contexto colonial, mas ela também teve um papel importante na conformação de uma identidade teuto-brasileira.

O crescimento urbano e a diferenciação social ocorreram ao mesmo tempo num contexto de desenvolvimento econômico; e a formação de segmentos médios revela também a heterogeneidade dos imigrantes no que diz respeito à profissão e à escolaridade. Artesãos de todos os tipos preferiram deixar o lote colonial para abrir oficinas familiares ou simplesmente atender as demandas por serviços especializados nas cidades. Por outro lado, a transformação dos produtos coloniais foi fundamental para a diferenciação interna do campesinato, envolvendo a posse de moinhos e serrarias. Mas poucos comerciantes de maior expressão tiveram origem rural ou artesanal. Outros estavam longe do perfil do imigrante comum porque possuíam recursos e/ ou alta escolaridade. A burguesia industrial teve sua origem na atividade comercial envolvendo importação e exportação, e possuía uma forte ligação com a Alemanha, e o ponto de partida para o enriquecimento foi a relação com os colonos. Na prática, os comerciantes (rurais e urbanos) formaram redes em que, numa ponta, estava o pequeno "vendeiro" local, muitas vezes um colono, e em outra, aqueles que possuíam o monopólio dos preços e dos transportes, cuja origem raramente se reportava à linha colonial.

$\mathrm{O}$ crescimento desse comércio, e depois da in- 
dústria, reforçou os laços com o país de origem, apontando para os debates e a literatura sobre os interesses germânicos no sul do Brasil. Abriu-se o mercado local para produtos alemães, e o mercado alemão, inclusive o financeiro, para os comerciantes. A industrialização, por sua vez, abriu o mercado de trabalho especializado para novos imigrantes mais qualificados. Toda essa movimentação ocorreu após a emancipação das colônias, com a instalação dos municípios, que trouxe para a região os "outros" - brasileiros não identificados com a colonização, ocupantes de cargos públicos e profissionais liberais com interesses políticos na nova ordem municipal instituída no final do Império.

O advento da República favoreceu a emergência de lideranças políticas teuto-brasileiras por dois motivos: a naturalização geral, sem burocracia e sem exigências nacionalistas, assegurada pelo Decreto $58^{\text {a }}$ de $14 / 12 / 1889$, e a permissão de alistamento eleitoral para os naturalizados alfabetizados que não conheciam a língua portuguesa, via a Decisão 38, de 14/3/1890. Não analisarei as disputas locais e os interesses políticos das elites teuto-brasileiras urbanas numa região que se tornou o principal colégio eleitoral do Estado, e de onde saiu a maioria dos governadores e senadores de Santa Catarina durante a Primeira República. Mas deve ser observado que tal situação de poder levou o princípio de germanidade para o campo político ${ }^{17}$ num momento de exacerbação dos nacionalismos (alemão e brasileiro) e da influência do pangermanismo com sua perspectiva transnacional.

Sem dúvida os empresários étnicos formaram grupos de interesse político e tiveram papel predominante na formatação do Deutschbrasilianertum e da identidade teuto-brasileira, em consonância com seus congêneres de outras regióes. Cada grupo com relevância política e econômica tinha um jornal, e as casas comerciais na rede rural-urbana eram pontos de venda de jornais e outras publicações periódicas em língua alemã, além de funcionar como locais da sociabilidade. Dessa forma, o discurso escrito do pertencimento étnico chegou até o colono comum por intermédio da imprensa e da convivência nas lojas e nas associações por onde circulava uma ideia de Deutschtum com duplo significado: econômico, referido ao progresso das co- lônias como produto do "trabalho alemão", e principal contribuição de cidadãos exemplares ao país de acolhida; e étnico, com ênfase na origem alemã e no "direito" de ser cidadão legítimo com língua e cultura distintas, num país que devia assumir sua pluralidade cultural. ${ }^{18}$ A perspectiva da assimilação está ausente do enunciado étnico, e o duplo pertencimento contido na categoria de identidade (teuto-brasileira) combina etnicidade (com seu referente de ascendência e cultura) e cidadania (e seu corolário de fidelidade ao Estado).

Enfim, o uso da etnicidade na política, num momento de consolidação da (então) pequena burguesia local, evidencia-se na mobilização em torno do cadastramento eleitoral dos colonos, na medida em que isso foi permitido aos que desconheciam a língua vernácula, numa rede de relações pessoais dominada por comerciantes e industriais devidamente naturalizados. No início do século $\mathrm{XX}$, um dos grupos políticos de Blumenau tentou criar um partido étnico com a rubrica de Volksverein (ou, em português, União Popular), mas a pressão nacionalista impediu sua concretização. O Deustschtum entrou na política na voz de teuto-brasileiros filiados aos partidos convencionais. Seus dois significados podem ser percebidos no volume comemorativo (o Gedenkbuch) anteriormente mencionado. Seu editor, Gottfried Entres, era um desses empresários étnicos, proprietário da Livraria Central, em Florianópolis, com conexóes na Alemanha, e que teve sua empresa depredada numa das manifestações antigermânicas que se seguiram à declaração da Guerra ao II Reich em 1917. O formato da publicação cumpre o que está apenso ao título - um olhar sobre o passado e o presente de Santa Catarina a partir do Deutschtum. O progresso das regiōes coloniais (e seu ponto de partida "pioneiro") sobressai no livro, reforçando o significado prático/econômico associado à germanidade (na sua versão do "trabalho alemão"); a política entra em cena por intermédio das lideranças mais em evidência na época, os irmãos Adolfo e Victor Konder, políticos vinculados ao Vale do Itajaí, respectivamente governador do Estado e ministro dos Transportes (do governo do presidente Washington Luis Pereira de Souza). Na formatação da ideologia étnica, porém, tem maior relevo a reivindicação da 
diferença cultural, observada nos diversos poemas distribuídos ao longo do livro, nas referências enfáticas ao valor das "escolas alemãs", à literatura em língua alemã, às associaçôes etc. E um breve artigo do editor fecha a publicação defendendo o Brasildeutschtum, invertendo a prioridade (a outra categoria é Deutschbrasilianertum, uma referência identitária), mas usando o argumento da fidelidade do alemão à sua nação de origem (termo tomado no seu sentido cultural e étnico, sem conotação de pertença política). A ideia de uma nova Heimat construída, nesse caso em Santa Catarina, perpassa o Gedenkbuch, em que membros da elite econômica e política teuto-brasileira distinguem-se na ampla "paisagem cultural" (civilizada) da colonização.

\section{Considerações finais}

O transnacionalismo tem sido bastante discutido nos estudos das migrações contemporâneas, tendo em vista a intensidade dos fluxos e seus reflexos nas políticas da identidade envolvendo a transposição de fronteiras internacionais. É considerado um fenômeno distinto da globalização que, nos termos de Kearney (1995, p. 548), refere-se a processos sociais, econômicos, culturais e demográficos que tem lugar no interior das nações mas as transcendem. Para Kearney, o transnacionalismo se sobrepõe à globalização mas tem um alcance mais limitado. Hannerz (1996, p. 6) também considera o transnacionalismo mais "modesto" do que globalização, e mais adequado para fenômenos que são muito variados, mesmo quando eles compartilham a característica de não estar contido num único Estado. Lembra também que muitas das ligações em questão não são "internacionais" no sentido de envolver naçōes, ou Estados, como atores corporativos; e os atores a considerar são indivíduos, grupos, movimentos, enfim, a diversidade de organizaçōes. E acrescenta que existe uma certa ironia no fato do termo transnacional dar atenção ao que ele nega, isto é, a contínua significação do nacional.

A questão das identidades (nacionais) é crucial na definição do atual Estado-nação transnacional, como se observa no texto de Schiller e Fouron (2000), mas este é apenas um dos temas abarcados pelo transnacionalismo. Aqui, a noção de Estado-nação transnacional não está sendo usada, mas os dados apontam para uma dinâmica transnacional envolvendo atores sociais que, de alguma forma, "transitam" entre dois Estados nacionais, desempenhando papel importante na definição da etnicidade teuto-brasileira. $\mathrm{O}$ trânsito pode ser tomado num sentido mais literal do deslocamento no espaço, ou numa forma metafórica abrangendo a circulação de ideias. Considero importante destacar essa forma de transnacionalismo (dada a germanidade do termo) operando no contexto histórico da imigração alemã, bastante diverso dos fenômenos migratórios atuais porque estava ligada à colonização e ao povoamento de terras devolutas no sul do Brasil.

No conjunto de dados sobre a colonização do Vale do Itajaí e nele, particularmente Blumenau, sobressai o fato de que a imigração, mesmo no século XIX, não representava necessariamente um rompimento definitivo com o país de origem. Aliás, o transnacionalismo já estava presente antes mesmo da fundação da colônia, dadas as conexões de Hermann Blumenau envolvendo o cônsul Sturz, o marquês de Abrantes e outras autoridades brasileiras, e figuras notáveis dos meios acadêmicos alemães preocupados com o futuro de seus compatriotas emigrantes.

As idas e vindas de Hermann Blumenau entre Alemanha e Brasil, antes e depois da fundação da colônia (em 1850), tinham o propósito de atrair emigrantes e, num dado momento, o casamento com uma compatriota, objetivo também de colonos comuns, conforme o relato de Klara Hermann. Se para muitos "colonos" tornar-se imigrante significava o não retorno à pátria, para outros, certamente os mais abonados, havia sempre a possibilidade de manutenção dos laços com parentes e amigos da Alemanha. Além disso, a notoriedade do Vale do Itajaí (como região de "colonização alemã") está associada à figura pública do seu fundador, ressaltada nos escritos produzidos sobre seu empreendimento, em geral publicados na Alemanha. A imagem da territorialização de uma nova Heimat no Brasil, por sua vez, transformou a região num lugar exemplar, modelo ideal da germanidade no estrangeiro, assinalado nas publicaçōes de viajantes, cientistas, pastores (como Gustav Stutzer) etc., e nos poemas e contos produzidos 
por literatos alemães e teuto-brasileiros. Aliás, outro personagem da colônia, tão notável quanto o fundador, foi o naturalista Fritz Müller, qualificado como "colono alemão" ligado ao Museu Nacional do Rio de Janeiro. Sua correspondência com Charles Darwin e o reconhecimento de sua obra científica também tiveram o efeito de tornar a colônia conhecida no exterior.

A persistência do fluxo imigratório e a existência de entidades alemãs voltadas para os imigrantes, como a sociedade de Proteção que enviou Hermann Blumenau ao Brasil, e a Haus des Deutschtums, que coeditou o Gedenkbuch organizado por Entres (1929), contribuíram para a circulação dos ideais da germanidade, assim como jornais, anuários e outras publicações teuto-brasileiras vendidas nas casas comerciais, urbanas e rurais. Isso evidencia outros mediadores étnicos - os comerciantes (e industriais) - que possuíam fortes ligações com a Alemanha, econômicas ou não, contribuindo para a consolidação de uma identidade teuto-brasileira. Seu postulado tinha caráter instrumental, político e econômico, igualmente alimentado pelo mesmo princípio de pertencimento étnico que deu relevo à crença numa neue Heimat assentada no binômio lar-língua materna e na percepção da diferença cultural em relação à sociedade nacional receptora. A dimensão cultural que caracteriza a etnicidade passa pela onipresença da noção de uma nova pátria territorializada no Vale do Itajaí. E, diante da frequência com que os literatos teuto-brasileiros usam elementos da paisagem como metáfora da diferença (cf. Seyferth, 2004), pode-se dizer que na neue Heimat o teuto-brasileiro é um alemão na sombra da palmeira. Afinal, para Klara Hermann o único elemento destoante na Joinville colonial (a primeira "cidadezinha alemã" por onde passou ao chegar ao Brasil) era a Alameda das Palmeiras.

\section{Notas}

1 Ver, por exemplo, as coletâneas organizadas por Cohen (1996); Cohen e Layton-Henry (1997).

2 Os volumes organizados por Barth (1969), Cohen (1974), Glazer e Moynihan (1975), Hutchinson e Smith (1996), Guiberneau e Rex (1997), e os trabalhos de Cardoso de Oliveira (1976), Eriksen (1993), Banks (1996) e Fenton (2008) proporcionam uma visão ampla das abordagens, às vezes conflitantes, a esse respeito.

3 As biografias ressaltam o título acadêmico (na área da química) e a posição de classe média (seu pai era engenheiro florestal), bem como a benemerência do seu projeto de colonização. Ver, Fouquet (1999).

4 Alguns anos depois, Sturz foi demitido do cargo por causa das suas críticas contundentes à escravidão, apesar da referida incompatibilidade ser compartilhada por algumas autoridades imigrantistas brasileiras.

5 A emigração de alemães para a América começou ainda no século XVIII, antes da independência dos Estados Unidos, atendendo à propaganda inglesa que procurou atrair indivíduos e famílias das denominações protestantes não luteranas. Havia, portanto, uma tradição de longa duração, continuada ao longo do século XIX. O verbo "desviar", por sua vez, era conjugado por imigrantistas brasileiros como o marquês de Abrantes, supondo alguma eficácia da propaganda de agenciadores e proprietários de empresas de navegação interessados no transporte dos "colonos".

6 A maioria dos imigrantes tinha poucos recursos, viajando com a família (portanto, havia crianças e idosos, os mais atingidos pelas doenças decorrentes da alimentação deficiente). Por outro lado, mesmo ao longo do século $\mathrm{XX}$, a imigração estava associada à pobreza $\mathrm{e}$, num dado momento (década de 1920), o imigrante foi (des)qualificado pelo governo brasileiro como aquele indivíduo que viaja na $3^{\mathrm{a}}$ classe dos navios.

7 Sobre os princípios que nortearam a colonização baseada na pequena propriedade familiar, implementado em terras devolutas, ver Roche (1969) e Seyferth (2009).

8 Os Stutzer são um caso exemplar, entre muitos outros: seus livros tiveram edições sucessivas entre 1886 e 1924. Num deles (Stutzer, 1886) aponta Blumenau como destino ideal para os emigrantes alemães.

9 A parte do texto de Lacmann relativa ao Vale do Itajaí foi traduzida e publicada na revista local Blumenau em Cadernos [XXXVIII (11), 1997], de onde foi extraído o trecho citado. A expressão deutsche Gebiet - território alemão - foi mantida no original pela tradutora. A publicação original - "Ritte und Rasttage in Südbrasilien" foi editada em Berlim por Dietrich Reimer, em 1906.

10 Ver Blumenau em Cadernos [L (6), 2009, p. 17], onde está publicado o trabalho de Stutzer intitulado "Na Alemanha e no Brasil - Retratos da colônia Blumenau" (editado originalmente na Alemanha, na forma de opúsculo). 
11 As duas efemérides ocorreram, respectivamente, em 2000 e 1999. O trabalho de Klara Hermann saiu em Blumenau em Cadernos, XLIII (11/12), 2002; XLIV (1/2), 2003.

12 Algumas casas remanescentes, consideradas mais "autênticas" nos padrões atuais, foram tombadas pelo patrimônio histórico em diversos municípios; e no contexto arquitetônico de alguns museus, como em Joinville, por exemplo, casas inteiras foram trazidas das áreas rurais, remontadas e mobiliadas para mostrar o que era o lar do "colono pioneiro" remediado.

13 Um bom exemplo desse tipo de relato é a história de vida escrita por Karl Kleine, intitulada "Blumenau de ontem: experiências e recordaçôes de um imigrante", parcialmente publicada na revista Blumenau em $\mathrm{Ca}$ dernos, XLI (11/12) e XLII (1/10).

14 Sobre a importância das publicações periódicas e suas repercussões nas ideias da germanidade no Vale do Itajaí, ver Seyferth (1982); a literatura, especialmente a poesia, foi analisada por Huber (1993) e Seyferth (2004).

15 A percepção do "lindo Itajaî" como pátria está assinalada num texto de Cristina Blumenau, escrito na década de 1930 e publicado em Blumenau em Cadernos, I (5), 1958.

16 Sobre os modelos de análise relativos aos "empresários étnicos”, ver a coletânea organizada por Waldinger, Aldrich e Ward (1990).

17 Sobre essa questão, ver Seyferth (1994).

18 Nos jornais mais diretamente influenciados pelo pangermanismo - caso do Der Urwaldsbote - a reivindicação do direito à diferença assumiu contornos racistas, defendendo a pureza étnica.

\section{BIBLIOGRAFIA}

ARONSON, Dan R. (1976), "Ethnicity as a cultural system: an introductory essay", in Francis Henry (ed.), Ethnicity in the Americas, Paris, Mouton.

BANKS, Marcus. (1996), Ethnicity: anthropological constructions. Londres, Routledge.

BARTH, Fredrik (ed.). (1969), Ethnic groups and boundaries. Bergen/Londres, Universitetsforlaget/ G. Allen A. Unwin.

CARDOSO DE OLIVEIRA, Roberto. (1976), Identidade, etnia e estrutura social. São Paulo, Pioneira.
COHEN, Abner. (1969), Custom and politics in urban Africa. Londres, Routledge. . (1974), Urban ethnicity. Londres, Tavistock.

COHEN, Robin (ed.). (1996), Theories of migration. Cheltenham, UK, Elgar.

COHEN, Robin \& LAYTON-HENRY, Zig (eds.). (1997), The politics of migration. Cheltenham, UK, Elgar.

D’AMARAL, Max T. (1950), Contribuição à história da colonização alemã no Vale do Itajaí. São Paulo, Instituto Hans Staden.

ENTRES, Gottfried (ed.). (1929), Gedenkbuch zur Jahrhundertfeier deutscher Einwanderung in Santa Catarina. Florianópolis, Livraria Central.

ERIKSEN, Thomas H. (1993), Ethnicity and nationalism: anthropological perspectives. Londres, Pluto Press.

FENTON, Steve. (2008), Ethnicity. Cambridge, Polity Press.

FOUQUET, Karl. (1950), "BIBLIOGRAFIA sobre o Vale do Itajaí". Centenário de Blumenau. Blumenau, Tipografia e Livraria Blumenauense.

(1999), "Vida e obra do Dr. Blumenau”. Blumenau em Cadernos, XL (10): 6-102.

GEERTZ, Clifford. (1964), "Ideology as a cultural system", in David Apter (ed.), Ideology and discontent, Nova York, The Free Press.

GLAZER, Nathan \& MOYNIHAN, Daniel P. (1963), Beyond the melting pot. Cambridge, Mass., Harvard University Press.

(EDS.). (1975), Ethnicity: theory and experience. Cambridge, Mass., Havard University Press.

GUIBERNAU, Montserrat \& REX, John (eds.). (1997), The ethnicity reader. Cambridge, Polity Press.

HANNERZ, Ulf. (1996), Transnational connections. Londres, Routledge.

HUBER, Valburga. (1993), Saudade e esperança. Blumenau, Editora da Furb.

HUTCHINSON, John \& SMITH, Anthony D. (eds.). (1996), Ethnicity. Oxford, Oxford University Press.

KEARNEY, M. (1995), "The local and the global: 
the anthropology of globalization and transnationalism". Annual Review of Anthropology, 24: 547-565.

NOGUEIRA, Rui A. (1947), Nacionalização do Vale do Itajaí. Rio de Janeiro, Biblioteca Militar.

ROCHE, Jean. (1969), A colonização alemã e o Rio Grande do Sul. Porto Alegre, Globo.

SCHILLER, Nina G. \& FOURON, Georges. (2000), "Laços de sangue: os fundamentos do Estado-nação transnacional", in Bela Feldman Bianco e Graça Capinha (orgs.), Identidades, São Paulo, Hucitec.

SEYFERTH, Giralda. (1982), Nacionalismo e identidade étnica. Florianópolis, Fundação Catarinense de Cultura. (1988), "Imigração e colonização alemã no Brasil: uma revisão da bibliografia". $B I B$ - Boletim Informativo e Bibliográfico de Ciências Socais, 25: 3-55.

(1994). "Identidade étnica, assimilação e cidadania: a imigração alemã e o Estado brasileiro". Revista Brasileira de Ciências Sociais, 26: 103-122.

(2004). "A ideia de cultura teuto-brasileira: literatura, identidade e os significados da etnicidade”. Horizontes Antropológicos, 22: 249-297.

(2009). "Imigrantes, colonos: ocupação territorial e formação camponesa no sul do Brasil”, in Delma P. Neves (org.), Processos de constituição e reprodução do campesinato no Brasil, Brasília/São Paulo, Nead/Editora da Unesp, vol. 2.

STUTZER, Gustav. (1886), Blumenau in Südbrasilien als Ziel der deutschen Auswanderung. Goslar, L. Koch.

WALDINGER, Roger; ALDRICH, Howard \& WARD, Robin (eds.). (1990), Ethnic entrepreneurs. Londres, Sage.

WEBER, Max. (1991), Economia e sociedade. Brasília, Editora da UnB, vol. 1.

WILLEMS, Emílio. (1946), A aculturação dos alemães no Brasil. São Paulo, Companhia Editora Nacional. 


\section{A DIMENSÃO CULTURAL DA IMIGRAÇÃO}

\section{Giralda Seyferth}

Palavras-chave: Imigração; Cultura; Etnicidade teuto-brasileira; Transnacionalismo.

Este trabalho tem por objetivo analisar aspectos da dimensão cultural da imigração, em consonância com etnicidade, focalizando um caso exemplar no contexto da colonização europeia em Santa Catarina - a "colônia Blumenau" - num período histórico marcado pela instauração da República (em 1889) e pelo aumento expressivo das entradas de estrangeiros no Brasil, permeado por um sistema mundial produzido, entre outras coisas, pela expansão imperialista. A partir desse caso é possível perceber como certas formas de circulação de bens culturais, inclusive ideias, valores e ideologias étnicas, contribuíram para a construção da etnicidade teuto-brasileira, apontando para a longa duração do transnacionalismo. O surgimento de subsistemas culturais naquela situação histórica de formação do Estado nacional republicano póe em evidência a difícil conciliação entre a nação e a diversidade cultural produzida pela imigração.

\section{THE CULTURAL DIMENSION OF IMMIGRATION}

\section{Giralda Seyferth}

Keywords: Immigration; Culture; German-Brazilian ethnicity; Transnationalism.

The aim of this work is to analyze aspects of the cultural dimension of immigration in conformity with ethnicity. It focuses an exemplary case in the context of European colonization in the Brazilian State of Santa Catarina - "colônia Blumenau" - during a historical period distinguished by the institution of the Republic (1889), and by the significant expansion of the entry of foreigners in Brazil, amidst a world system resulting, among other things, from imperialist expansion. This case shows how forms of circulation of cultural goods, including ideas, values, and ethnic ideologies, have contributed to the construction of some German-Brazilian ethnicity, indicating the long duration of transnationalism. The constitution of cultural subsystems in the historical situation where the $\mathrm{Na}$ tional Republican State was being established shows the difficulties in conciliating nation and cultural diversity resulting from immigration.

\section{LA DIMENSION CULTURELLE DE L'IMMIGRATION}

\section{Giralda Seyferth}

Mots-clés: Immigration; Culture; Appartenance ethnique teuto-brésilienne; Transnationalisme.

Ce travail aborde, selon l'origine ethnique, les aspects de la dimension culturelle de l'immigration. Il se concentre sur un cas exemplaire dans le contexte de la colonisation européenne dans l'état brésilien de Santa Catarina - la "colonie de Blumenau " - au cours d'une période historique marquée par l'instauration de la République (en 1889) et par l'augmentation significative de l'entrée des étrangers au Brésil, imprégnée par un système mondial découlant, d'entre autres, de l'expansion impérialiste. À partir de ce cas, il est possible de percevoir comment certaines formes de circulation de biens culturels - y compris les idées, les valeurs et les idéologies ethniques - ont contribué à la construction de l'ethnie teuto-brésilienne, indiquant vers la longue durée $\mathrm{du}$ transnationalisme. L'émergence de sous-systèmes culturels dans le cadre de la situation historique de formation de l'État national républicain met en évidence la difficile conciliation entre la nation et la diversité culturelle produite par l'immigration. 